\title{
USO DE ULTRASSOM PARA A PRODUÇÃO DE BIODIESEL EM MODO CONTÍNUO UTILIZANDO LIPASES
}

\author{
M. C. P. ZENEVICZ ${ }^{1}$, C. M. T. SANTIN ${ }^{1}$, D. de OLIVEIRA ${ }^{1}$, FURIGO JR, A. ${ }^{1}$, J. V. de \\ OLIVEIRA ${ }^{1}$.
}

1 Universidade Federal de Santa Catarina, Departamento de Engenharia Química e Engenharia de Alimentos

E-mail para contato: maracristinazenevicz@gmail.com

\begin{abstract}
RESUMO - O processo contínuo proporciona um menor custo de produção, a qualidade do produto é uniforme, facilita o controle do processo e, diminuindo o volume do reator, reduz-se o tempo de retenção necessário para atingir conversões desejadas. O objetivo deste trabalho foi o estudo da produção de biodiesel em banho de ultrassom e modo contínuo. Para as reações de esterificação utilizou-se como substratos: ácido graxo vegetal (lote: PA 1060.525 A12); álcool etílico; Novozym 435 e Lipozyme TL IM. O sistema experimental utilizado neste trabalho consiste num reator de vidro empacotado, submerso em um banho de ultrassom. Estudou-se as razões molares (ácido graxo/etanol) 1:3 e 1:6 para as vazões de alimentação de substrato de 2,5 e $5 \mathrm{~mL} / \mathrm{min}, 65^{\circ} \mathrm{C}$ e 132 Watts de potência ultrassônica. O excesso de álcool favoreceu a reação de esterificação sendo que as melhores conversões $(95 \% \mathrm{em}$ $6 \mathrm{~min}$ de reação) foram obtidas para a razão molar 1:6, vazão de $2,5 \mathrm{~mL} / \mathrm{min}$ e mantendo-se estáveis. O aumento da vazão de alimentação diminuiu as conversões ficando em $87 \%$ e a substituição da Novozym 435 pela Lipozyme TL IM não apresentou conversões satisfatórias.
\end{abstract}

\section{INTRODUÇÃO}

O interesse industrial por tecnologias enzimáticas vem aumentando gradativamente, em meios não convencionais, as quais ampliaram consideravelmente o potencial de aplicação das enzimas como catalisadores em processos industriais (Castro et al. 2004). As lipases são enzimas naturalmente presentes no organismo dos seres vivos, responsáveis pelo metabolismo de óleos e gorduras. Estas enzimas possuem um grande potencial biotecnológico, pois em meio aquoso catalisam a hidrólise de triacilgliceróis, e em condições de baixa quantidade de água podem promover também reações de esterificação, interesterificação e transesterificação (Jaeger et al. 1999).

O biodiesel (éster monoalquílico de ácido graxo) produzido a partir de óleos vegetais, gorduras animais e óleos de microalgas por transesterificação ou esterificação com álcoois de cadeia curta tem sido visto como promissora fonte renovável de combustíveis devido à sua biodegradabilidade, baixa toxicidade, renovabilidade e menor dependência de produtos petrolíferos (Encinar, 1999).

Os ésteres alquílicos que compõem o biodiesel podem ser sintetizados via transesterificação, utilizando TAGs e álcoois, ou via esterificação, utilizando AGLs e álcoois. 
A reação de transesterificação ocorre em três etapas, onde são produzidos diacilgliceróis e monoacilgliceróis como intermediários de reação, e glicerol como subproduto, enquanto que a esterificação ocorre em uma única etapa com a formação de água como subproduto.

$\mathrm{Na}$ busca por novas técnicas que possam melhorar o rendimento de processos industriais, a tecnologia que emprega ultrassom vem se mostrando como uma alternativa promissora devido aos benefícios que pode promover, e à sua aplicabilidade em uma vasta gama de atividades (Kwiatkowska et al. 2011). O processo de produção de biodiesel utilizando ultrassom vem como alternativa ao processo convencional de produção, uma vez que as cavitações (formação, aumento e implosão de bolhas no meio reacional) geradas pelo ultrassom aumentam a miscibilidade entre os reagentes, fornecem energia necessária para a reação, reduzem o tempo de reação e a quantidade de reagentes necessária e aumentam o rendimento e a seletividade da reação (Yu et al. 2010).

Levando-se em consideração a importância do estudo dessa nova tecnologia, com base nos aspectos expostos anteriormente, este trabalho visa explorar o potencial do ultrassom para produção de biodiesel em sistema livre de solvente orgânico, por meio do processo de esterificação enzimática de ácido graxo vegetal, em reator contínuo, visando uma diminuição de tempo, custos e gastos energéticos.

\section{MATERIAL E MÉTODOS}

\subsection{Especificação dos materiais}

As lipases utilizadas para este trabalho foram as lipases comerciais imobilizadas Lipozyme TL IM e Novozym 435 adquirida da Novozymes Brasil. Como substratos para esterificação foi utilizado o ácido graxo vegetal (lote: PA 1060.525 A12) produzido por SGS Agricultura e Indústria Ltda, em Ponta Grossa - PR; Álcool etílico (Merck, 99,9 \% de pureza). Para a determinação da acidez das amostras (A $(\% \mathrm{~m})$ ) foram utilizados, hidróxido de potássio (Vetec); Etanol: Éter etílico (1:1 v/v) (95\% de pureza, Vetec); Fenolftaleína (Nuclear).

\section{PROCEDIMENTO EXPERIMENTAL}

\subsection{Produção de biodiesel enzimático em sistema de ultrassom livre de solvente orgânico em modo contínuo}

O aparato experimental utilizado neste trabalho consiste num reator de vidro com 13 $\mathrm{mm}$ de diâmetro interno, comprimento de $171 \mathrm{~mm}$ e volume de $29 \mathrm{~mL}$ empacotado com a lipase, submerso em um banho de ultrassom (Unique UltraSonicCleaner, modelo: USC$1800 \mathrm{~A}$, frequência de $40 \mathrm{KHz}$, potência de $132 \mathrm{~W}$ ), alimentado com a mistura reacional de ácido graxo/álcool etílico (substrato), com uso de aproximadamente 9,7 g de lipase. A Figura 1 abaixo apresenta o aparato experimental utilizado neste trabalho. 


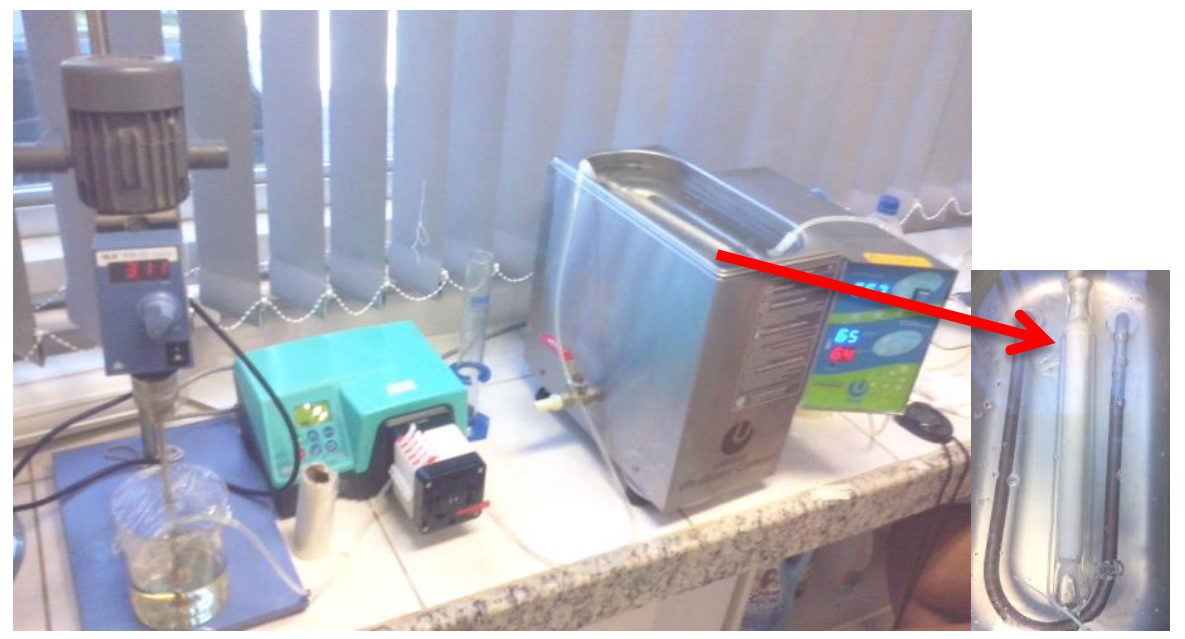

Figura 1 - Aparato experimental utilizado para a produção de biodiesel enzimático por esterificação em modo contínuo e banho de ultrassom.

O procedimento experimental consistiu primeiramente no empacotamento do reator com a enzima e após acoplou-se o reator ao sistema reacional e imergiu-o no banho de ultrassom já acondicionado na temperatura e potência a ser utilizada no experimento, iniciouse o bombeamento contínuo dos substratos carga ácida (AGL) e álcool etílico, previamente homogeneizados sob a mesma agitação, durante a reação, por um agitador mecânico (modelo RW 20 D, IKA) inserido no frasco contendo a mistura reacional, a uma dada razão molar (AGL:álcool) e vazão volumétrica de alimentação do substrato, até o completo preenchimento do sistema reacional, usando uma bomba peristáltica MARLOW 323. A bomba é utilizada para deslocar a mistura reacional para a zona de reação e manter a pressão do sistema. $\mathrm{O}$ cálculo do volume do reator foi realizado através de seu diâmetro interno e comprimento utilizado. A porosidade do leito foi determinada de acordo com Dalla Rosa (2009) adicionando o cômputo da porosidade interna da enzima. Neste caso, a porosidade do leito deve considerar o volume do soluto (enzimas) que ocupa o leito do reator e o volume de poros da enzima, como mostra a seguinte equação:

$$
\varepsilon_{L}=1-\left(\frac{V_{S}-V_{P}}{V_{R}}\right)
$$

Onde:

VS é o volume ocupado pelas enzimas no leito do reator;

VR é o volume do leito do reator;

VP é o volume de poros das enzimas que ocupam o leito do reator.

Conforme Dalla Rosa (2009), para o cálculo do volume de soluto (VS) obteve-se as seguintes informações: número de unidades de enzima em determinada massa (realizado manualmente) e diâmetro médio das partículas da enzima (calculado pela média da observação do resultado de análise de MEV - Microscopia Eletrônica de Varredura). 
O volume de poros (VP) foi então multiplicado pela massa da amostra de enzima empacotada no leito do reator. Neste caso, foi adotado como valor de volume de poros: VP1 = dado pela ficha técnica do fabricante da enzima $(0,5 \mathrm{~mL} / \mathrm{g})$. O tempo de residência é dado pela porosidade do leito multiplicado pelo seu volume e dividido pela vazão de alimentação de substratos a serem utilizados no processo (Dalla Rosa, 2009).

$\tau=\frac{\varepsilon_{L} * V_{R}}{q}$

Após a mistura reacional percorrer toda a extensão do reator, a coleta das amostras foi realizada em frascos de amostragem (previamente pesados) após decorrido um tempo de residência da mistura na zona reacional. Em seguida, procedia-se a análise por titulação da quantificação dos ésteres etílicos.

\subsection{Conversão dos ácidos graxos vegetais em ésteres obtidos por meio de reação de esterificação}

A técnica da titulação foi realizada de acordo com a IUPAC 2.201 o AOCS Cd 3d - 63 e consiste na determinação da acidez do meio, devido a presença dos ácidos graxos livres. Estes ácidos são capazes de reagir com a solução de hidróxido de potássio e o resultado obtido é expresso em mg $\mathrm{KOH}$ por (g) de amostra e normalmente a acidez titulável corresponde ao dobro do percentual do ácido correspondente da amostra. Este procedimento é realizado com a pesagem de uma alíquota de $\pm 2 \mathrm{~g}$ de amostra em um erlenmeyer de $300 \mathrm{~mL}$. Em seguida, adiciona-se $50 \mathrm{~mL}$ de uma solução etanol: éter etílico (v/v), homogeneizado e à esta, adiciona-se 3 gotas de indicador fenolftaleína 1\% para indicar o ponto de viragem (mudança de cor) na titulação com solução de $\mathrm{KOH} 0,1 \mathrm{~N}$. A amostra não necessita de tratamento prévio por esta técnica, sendo esta, diretamente coletada do reator para ser analisada, sem necessidade de secagem para evaporação da água ou do excesso de solvente. $\mathrm{O}$ índice de acidez é determinado pela Equação 3.

$A=\frac{56,1 \times V_{K O H} \times M_{K O H}}{M_{\text {amostra }}}$

Onde:

A é índice de acidez (mg KOH/g);

56,1 é o equivalente grama do $\mathrm{KOH}$;

$\mathrm{V}_{\mathrm{KOH}}$ é o volume de $\mathrm{KOH}$ gasto na titulação (L);

$\mathrm{M}_{\mathrm{KOH}}$ é molaridade do $\mathrm{KOH}$ usado na titulação (mol/L);

$\mathrm{M}_{\text {amostra }}$ é a massa de amostra utilizada para titular $(\mathrm{g})$.

Para determinar a o percentual de conversão do ácido graxo vegetal é necessário determinar a acidez da solução alimentada no reator. Determinando-se a acidez inicial e final 
(após a reação) é possível determinar a conversão de ácidos graxos, que está diretamente relacionada com o teor em ésteres da mistura. O cálculo para conversão dos ácidos graxos é apresentado na Equação 4.

$X(\%)=\left(\frac{A_{i}-A_{t}}{A_{i}}\right) \times 100$

$\mathrm{A}_{\mathrm{i}}$ é índice de acidez inicial;

$\mathrm{A}_{\mathrm{t}}$ é índice de acidez final.

A acidez no tempo t é calculada pontualmente, de acordo com a cinética realizada, ou seja, assim que a amostra é coletada já é devidamente pesada e titulada evitando a evaporação dos componentes.

\section{RESULTADOS E DISCUSSÕES}

Com objetivo em produzir ésteres etílico (biodiesel) via esterificação enzimática em reator continuo em banho de ultrassom e livre de solvente orgânico, investigou-se o efeito da razão molar ácido graxo/etanol, vazão de alimentação e enzima sobre a conversão em ésteres etílico utilizando um ácido graxo vegetal com índice de acidez inicial de $221,12 \mathrm{mg} \mathrm{KOH} / \mathrm{g}$.

A Figura 2 mostra a cinética do efeito da razão molar ácido graxo/etanol $(1: 3 ; 1: 6)$ sobre a conversão em ésteres etílicos \% nas condições fixas de $65^{\circ} \mathrm{C}$, potencia ultrassônica $100 \%$, vazão de alimentação de $2,5 \mathrm{~mL} / \mathrm{min}$ e lipase Novozym 435 . Pode-se observar que o excesso de álcool favoreceu a reação de esterificação sendo que as melhores conversões $(95 \%$ em 6 min de reação) foram obtidas para a razão molar 1:6, vazão de $2,5 \mathrm{~mL} / \mathrm{min}$ e mantendo-se estáveis no decorrer de todo o tempo reacional. Estes resultados condizem com resultados de Santin (2013) onde estudou o efeito da razão molar (1:1; 1:3) e álcool (Etano/Metanol) sob a conversão em ésteres utilizando o mesmo ácido graxo utilizado neste trabalho em modo contínuo, ultrassom e reator de polietileno com vazão de alimentação de $0,5 \mathrm{ml} / \mathrm{min}, 65^{\circ} \mathrm{C}$, potência ultrassônica $100 \%$, e verificou que a reação de esterificação com etanol apresentou vantagens sobre o metanol, proporcionando melhores conversões em ésteres. Em relação á razão molar a reação com razão molar 1:3 (AGL/etanol) foi que apresentou melhores resultados em 27 a 81 min obteve-se 88,26 e 86,88\% de conversão.

Do ponto de vista termodinâmico, o excesso de reagente tenderia a deslocar o equilíbrio da reação para os produtos, isto é, esperar-se-ia um aumento na conversão com o aumento do excesso de álcool (Srivastava et al. 2003). Com base aos resultados obtidos na figura 1 optouse em realizar uma nova cinética fixando a razão molar ácido graxo: etanol 1:6, potência ultrassônica $100 \%, 65^{\circ} \mathrm{C}$, lipase Novozym 435 e aumentando a vazão de alimentação para 5 $\mathrm{mL} / \mathrm{min}$. 


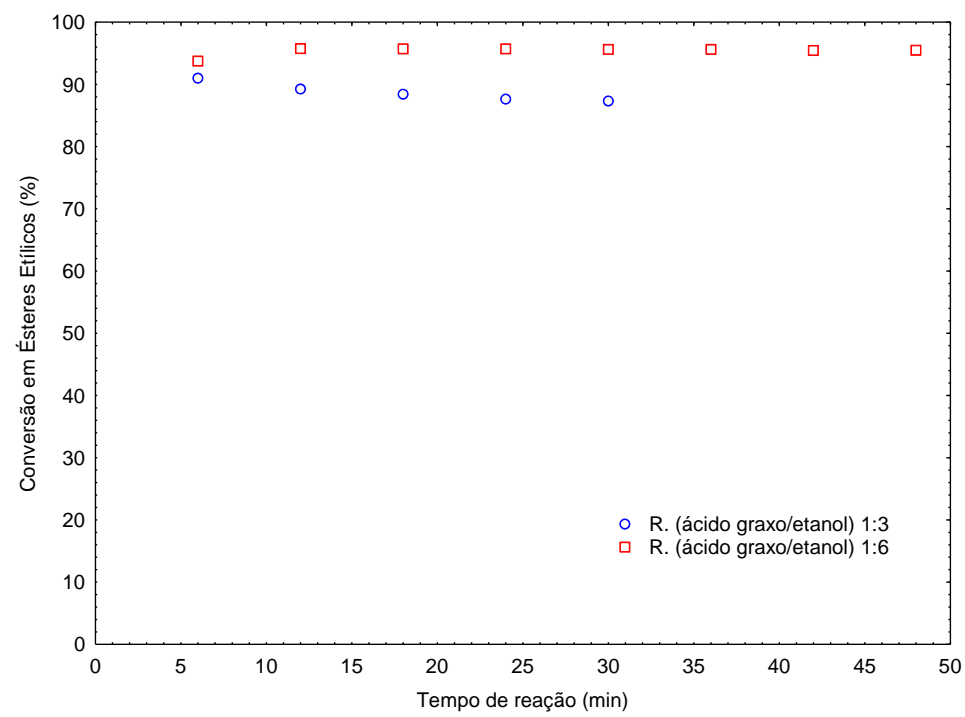

Figura 2- Cinética do efeito da razão molar sobre a conversão em ésteres utilizando um ácido graxo vegetal como substrato em modo contínuo em banho de ultrassom. Razão molar (carga ácida/etanol) 1:3 e 1:6, vazão de alimentação de substrato $2,5 \mathrm{~mL} / \mathrm{min}, 65^{\circ} \mathrm{C}$, potência ultrassônica de $100 \%$ e lipase Novozym 345 imobilizada.

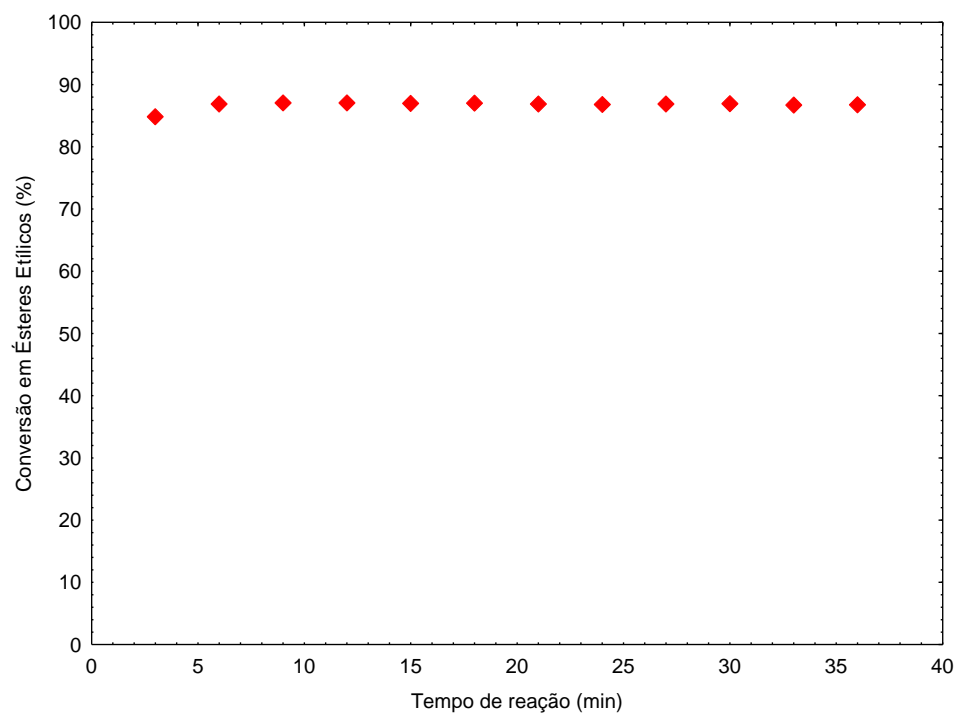

Figura 3- Cinética do efeito do aumento da vazão de alimentação sobre a conversão em ésteres etílicos em modo contínuo e banho de ultrassom. Razão molar (carga ácida/etanol) 1:6, vazão de alimentação de substrato $5 \mathrm{~mL} / \mathrm{min}, 65^{\circ} \mathrm{C}$, potência ultrassônica de $100 \%$ e lipase Novozym 345 imobilizada.

Através da Figura 3 observa-se que o aumento da vazão de alimentação diminuiu as conversões quando comparado com a vazão de $2,5 \mathrm{~mL} / \mathrm{min}$ ficando em $87 \%$ logo aos 5 min de reação mantendo-se estáveis ao decorrer do tempo reacional, isto devido que se aumentarmos a vazão de alimentação o substrato, o mesmo passará mais rapidamente no interior do reator diminuindo o tempo de contato com a enzima. Conforme Trentin (2010), ao aumentar o fluxo volumétrico de alimentação dos reagentes, a conversão pode ser reduzida, fato atribuído ao menor tempo de residência. 
Resolveu-se então realizar uma nova cinética fixando as variáveis otimizadas e substituindo a lipase Novozym 435 pela Lipozyme TL IM na tentativa de reduzir o custo da produção de biodiesel.

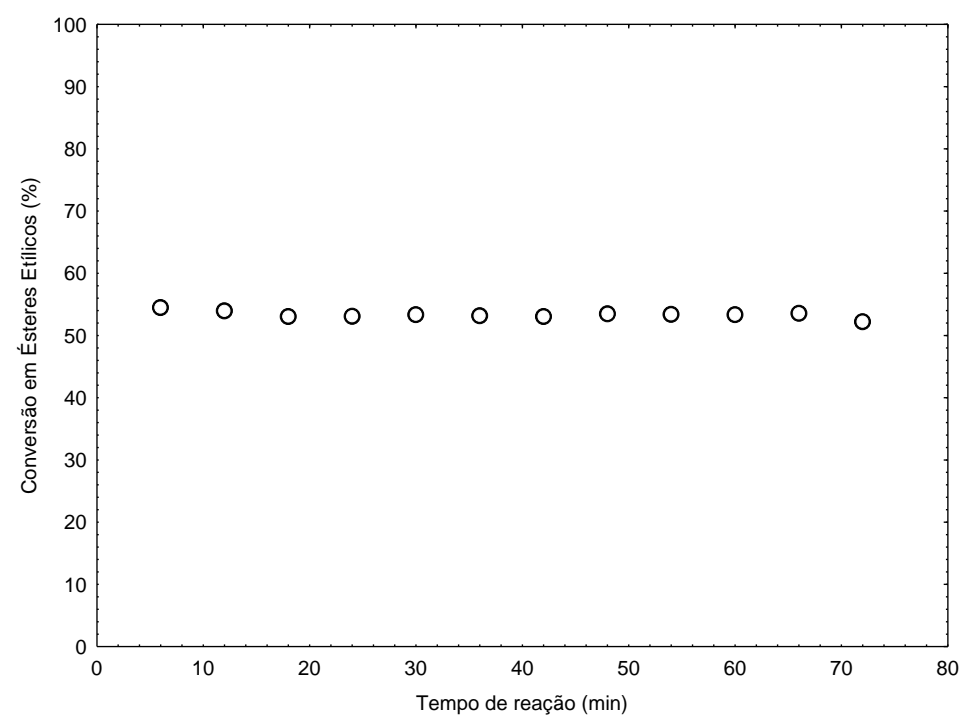

Figura 4- Conversão de ésteres etílicos com uso da enzima Lipozyme RM IM como catalisador através da esterificação em modo contínuo em banho de ultrassom. Razão molar (carga ácida/ etanol) 1:6, vazão de alimentação de substrato $2,5 \mathrm{~mL} / \mathrm{min}, 65^{\circ} \mathrm{C}$, potência ultrassônica de $100 \%$.

Através da Figura 4 nota-se que a substituição da lipase Novozym 435 pela Lipozyme RM IM como catalizador a diferença na conversão e muito grande, não apresentou conversões satisfatórias.

Em comparação com os métodos de síntese química, a produção de biodiesel catalisada por enzimas (lipases) oferece muitas vantagens, tais como uma elevada seletividade, menor consumo de energia, menos produtos secundários e resíduos, evitando formação de sabão e fácil recuperação de glicerol e de catalisadores. No entanto, o custo da lipase é o maior obstáculo para a utilização de lipases em produção de biodiesel industrial (Veljkovi'c et al., 2012).

\section{CONCLUSÕES}

Em vista ao desenvolvimento de novas técnicas que possibilitem a produção de biodiesel enzimático em ultrassom livre de solventes, são poucos os trabalhos disponíveis na literatura ressaltando importância desta pesquisa. Através da reação de esterificação notou-se que o excesso de álcool favoreceu a reação de esterificação sendo que as melhores conversões (95\% em 6 min de reação) foram obtidas para a razão molar 1:6, vazão de $2,5 \mathrm{~mL} / \mathrm{min}$ e mantendo-se estáveis no decorrer de todo o tempo reacional. O aumento da vazão de alimentação diminuiu as conversões ficando em $87 \%$ e a substituição da Novozym 435 pela Lipozyme TL IM não apresentou conversões satisfatórias. 


\section{REFERÊNCIAS}

CASTRO, H. F.; MENDES, A. A.; SANTOS, J. C. Modificação de óleos e gorduras por biotransformação. Química Nova, v. 27, p. 146-156, 2004.

DALLA ROSA, C.D., MORANDIM, M.B., NINOW, J.L., OLIVEIRA, D., TREICHEL, H., OLIVEIRA, J.V. Continuous lipase-catalyzed production of fatty acid ethyl esters from soybean oil in compressed fluids. Bioresource Technol., v. 100, p. 5818-5826, 2009.

ENCINAR, J. M.; GONZALEZ, J. F.; SABIO, E.; RAMIRO, M. J. Preparation and Properties of Biodiesel from Cynara cardunculus L. Oil. Ind. Eng. Chem. Res., v. 38, p. 2927-2931, 1999.

GOLE, V. L.; GOGATE, P. R. A review on intensification of synthesis of biodiesel from sustainable feed stock using sonochemical reactors. Chem. Eng. Process., v. 53, p. 1-9, 2012.

JAEGER, K. E.; DIJSTRA, B. W.; REETZ, M. T. Bacterial Biocatalist: molecular biology, three dimensional structures and biotechnological applications of lipases. Anu. Ver. Microbiol., v. 53, p. 315-351, 1999.

KWIATKOWSKA B.; BENNETT, J.; AKUNNA, J.; WALKER, G. M.; BREMNER D. H., Stimulation of bioprocesses by ultrasound. Biotechnol. Adv., v.29, p. 768-780, 2011.

SANTIN, C. M. Síntese de biodiesel pela transesterificação e esterificação enzimática em sistema livre de solvente em banho de ultrassom. Tese de Doutorado. Universidade Regional Integrada do Alto Uruguai e das Missões - URI, Erechim, RS, Brasil, 2013.

SRIVASTAVA, S.; MADRAS, G.; MODAK, J. Esterification of myristic acid in supercritical carbon dioxide. J. Supercrit. Fluids, 27, p. 55-64, 2003.

TRENTIN, C. M. Estudo da cinética de transesterificação não-catalítica de óleo de soja com co-solvente em reator micro tubo. Dissertação de Mestrado, Universidade Regional Integrada do Alto Uruguai e das Missões - URI, Erechim, RS, Brasil, 2010.

VELJKOVI'C, V.B.; AVRAMOVI' C, J. M.; STAMENKOVI'C, O. S. Biodiesel production by ultrasound-assisted transesterification: State of the art and the perspectives. Renew. Sust. Energ. Rev., v. 16, p. 1193-1209, 2012.

YU, D.; TIAN, L.; WU, H.; WANG, S.; WANG, Y.; MA, D.; FANG, X. Ultrasonic irradiation with vibration for biodiesel production from soybean oil by Novozym 435 . Process. Biochem., v. 45, p. 519-525, 2010. 